\title{
An Investigation into the Management of Online Teaching and Learning Spaces: A Case Study Involving Graduate Research Students
}

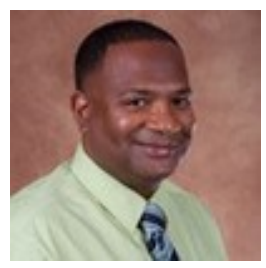

Rohan Jowallah

University of Central Florida, USA

\section{Abstract}

This research evaluates the strategies implemented to support the research activities of postgraduate students pursuing online master's programs in the University of the West Indies Open Campus, as well as the activities of their supervisors. The three main strategies employed were (1) the use of a web-based 'teaching-learning space' to facilitate asynchronous interaction between students and their supervisors; (2) the provision of a scheduling tool to facilitate the planning of one-on-one meetings via a synchronous web-conferencing tool; and (3) the organization of research seminars using the same web-conferencing tool.

This research used Moore's theory of transactional distance and social cognitive theoretical framework to guide the project. Moore's model reemphasizes the need for stronger forms of communicating for online students, whereas the cognitive framework focuses on the need for social interaction among learner and teacher. Participants were graduate students $(\mathrm{n}=34$ ). All participants were required to complete a questionnaire online. Data were also collected from postings in discussion forums. Overall, notwithstanding limitations, the data shows there are benefits to be gained from conducting student research activities in an online environment.

Keywords: Online interaction; higher education; asynchronous and synchronous communication 


\section{Introduction}

The past decade has seen the rapid development of online educational programs in universities. One reason for this increase is the grouth of the Internet and technological advancements that support online learning spaces (J ohnson \& Aragon, 2003). Traditionally, students who engaged in a research unit for their degree were assigned a research supervisor with whom they met one-on-one face-to-face. In addition, students could attend informal meetings with their supervisors and fellow students within a physical location. The lack of one-on-one face-to-face within the online learning environment requires universities to be innovative in creating interactive learning spaces to support research students within the online environment. In responding to the need for creative and interactive learning spaces, many universities have used various technological tools.

By employing these technological tools, many institutions have "...developed innovative learning strategies..." (McPherson \& Baptista, 2004, p. 148). These "innovative learning strategies" have created flexible methods of delivery for courses (Ragan, Lacey, \& Nagy, 2000), opportunities for the delivery of courses by highly qualified staff (Banks, Moon, \& Wolfenden, 2009), and have given students a high quality of education without geographic restrictions. Furthermore, the introduction of these ground-breaking technologies has created an ideological transformation for the educator for the conceptualization and development of knowledge online (Mok \& Cheng, 2000). Mok and Cheng (2000) view this change as the "demonopolisation of teaching" which is the shifting from the 'teacher focus approach' to the 'studentcentered learning approach'. Therefore, it will be imperative for universities to consider how they will use new technologies to enhance online pedagogy to improve support for research students.

\section{The Context of the Research Problem}

The UWI Open campus came into existence four years ago after major restructuring with other sectors within The University of The West Indies. In J anuary 2010, The UWI Open Campus enrolled over seventy students in its online Master's Literacy Program. For the completion of a Master of Education degree, students were required to complete a research project.

For the research component, all students were assigned a research supervisor (RS); each research supervisor was assigned four students. As supervisors, they were responsible for supporting the students' research agenda, guiding the research process, and aiding students in their research management. An assigned research coordinator provided quality assurance and supervision.

During the third week of the research course, the researcher conducted a small online survey that solicited concerns from 34 students. The data collected was analysed using themes; the following themes emerged: the need for improved research supervisor's support, time management, understanding the research process. Based on the findings 
from the survey, the researcher supervisors met on three occasions to decide on an appropriate means to address students' concerns. The consensus was that research supervisors plan and implement asynchronous and synchronous communication to encourage interaction between themselves and their students. This form of interaction should take place within an online forum with live discussion with their group of students, one-to-one meetings with students, and compulsory participation of students in live research proposal seminar presentations.

\section{Significance of the Problem}

There is a need for online social interaction especially within the context of universities that are moving their degree programs online. Many universities have neglected to ensure that courses delivered online have adequate interaction for the construction of knowledge. The implementation of technological tools can strengthen interaction; however, technology must be used within the framework of planned human interaction. Without planned human interaction, various gaps will be created that could hinder the learner and instructor. Consequently, it is essential that activities are planned to simulate social interaction online. Wei et al. (2012, p. 529) state “... social presence has significant effects on learning interaction that in turn have significant effects on learning performance."

This research is important because it focuses on the need for course instructors to be proactive and make changes in their mode of delivery to address gaps in their instructional approach for increased interaction within the online learning environment. This study could also prove to be a starting point for many universities seeking to enhance their online courses and improve online interaction.

Finally, The UWI Open Campus is a new organization; therefore, it is important to find innovative methods to respond to the diverse learning needs of the students who are located in various Caribbean countries. It is the researcher's view that this should be done in a responsible manner using research as a means to evaluate strategies. The researcher used the research questions below to guide the examination and evaluation of the strategies implemented in the online learning environment.

\section{Research Questions}

- In what ways did setting up synchronous and asynchronous tools improve the learning experiences of online research students?

- How did the inclusion of asynchronous and synchronous tools improve interaction between students and their research supervisors?

- What were some of the difficulties experienced by students in using the asynchronous and synchronous interactive strategies employed to support them? 


\section{Theoretical Frameworks}

A social cognitive theoretical framework guided the research. According to Yanghee and Baylor (2006), "Social-cognitive theories highlight that teaching and learning are social activities and that involves interaction with teachers, peers, and instructional materials that influence the cognitive and affective development of the learners". The above mentioned framework makes direct connections to the need for social interaction between the learner and the instructor. Based on this framework the researcher designed the research process within this social context and need for interaction. This need for interaction is affirmed by Perkins (2001) who postulates that strategies implemented without giving consideration to the social-cognitive dimension of learning will not achieve its objectives. Seminal psychologists such as Piaget and Vygotsky affirm that interaction is fundamental to the learning and development process (Yanghee \& Baylor, 2006). The research also utilized Moore's theory of transactional distance, which suggests that distance learning could lead to gaps that could create potential barriers between the learner and the instructor (Moore \& Kearsley, 1996).

\section{Literature Review}

Online learning technological advancements allow facilitators and students to work collaboratively within the learning environment. Such collaborative learning promotes the construction of knowledge. In spite of these benefits, however, there is resistance to the development of online delivery by some academics. This resistance may be the result of a lack of expertise to conceptualize and develop the online environment (Zhao et al., 2002); ideological assumptions that teaching cannot be done using the online format (Baecher, 2011); or the lack of allocated training time to develop the required skills (Vannatta, 2000). When initiating the online delivery of any program, developers must acknowledge that a different level of proficiencies for instructors than what is required in the face-to-face traditional approach will be necessary. These proficiencies will require online tutors to be creative teachers who are supportive of the learner, skilled in monitoring the learning environment, able to motivate and stimulate the learner, and able to create critical learning interaction between themselves and their students (Fein \& Logan, 2003). Furthermore, today's learners are able to access various technologies that will allow them to retrieve information in 'real time.' Consequently, it will be essential for universities to develop "a style of education that excites and engages students..." (Girard et al., 2007, p. 46).

Educators who have found effective ways to promote exciting and engaging education incorporate synchronous and asynchronous forms of communication (Girard, 2007). The fusion of both communication forms could lead to greater virtual collaboration between the facilitator and the learners and construct a community of producers of knowledge. Leung et al. (2007) validate the inclusion of both synchronous and asynchronous by stating that both systems provide "complimentary ways of communication and interactions for different teaching and learning principles" (p. 634). 
Some academics suggest that within the online learning environment interaction and socialization between teachers and learners are limited. Such views do not take into account the technological advancements of ICTs and their capacity to support meaningful learning both individually and interpersonally. These improved technological advancements have also enhanced the social presence needed online, improved instructional effectiveness, and helped instructors and their students to work collaboratively (Aragon, 2003). McLennan (1999) describes social presence as "the degree to which participants are able to project themselves effectively within the medium” (p. 40). Gunawardena and Zittle (1997) simplify McLennan's description by stating social presence is 'the degree to which a person is perceived as a 'real person' in mediated communication" (p. 9).

The development of social presence online creates a comfort zone for learning, increases informal and formal exchange, increases the inclusion of learners, improves collegial interaction, and enhances cognitive interaction within the online learning environment (Whiteman, 2002; Newberry, 2001; Rourke et. al., 1999). Importantly, Aragon (2003) warns that individuals who are separated by physical or geographic distance are at risk of having limited social presence; therefore, attention should be given to social presence within the online learning environment to avoid negative consequences.

\section{Methodology}

\section{Research Sample}

All students enrolled in the class were asked to participate in an online questionnaire; 34 of the 70 students completed the questionnaire. All data collected had non-identifiers to ensure anonymity. Data was also collected from the online learning environment, specifically the learning exchange, throughout the course which lasted seven months. Influenced by a social cognitive theoretical framework and Moore's theory of transactional distance, the researcher chose the case study design to guide the research process.

Both approaches lend themselves to the exploration of socially constructed data. By using the case study design, the researcher was able to use the qualitative method of data collection to solicit the perspectives of participants in relation to their online experiences. Data was also collected in quantitative form from the questionnaires. By combining both forms of data, the researcher was able to offset the limitations associated with qualitative and quantitative methods of data collection. The researcher is also aware of the limitation associated with the generalization of these findings and the high level of subjectivity associated with undertaking a case study design. 
Consequently, the researcher took procedures to ensure that the instrument used was valid.

Based on the timeframe available for this study and the nature of the study, the researcher decided to maximize the use of online questionnaires for the research students. The questionnaires were designed to gain open responses rather than closed. A second source of data collection included the students' forum and recorded seminar sessions. The researcher had intended to conduct in-depth interviews, however, upon deliberation, decided that the interviews should be implemented at the end of the students' final trimester.

\section{Analysis of Data}

Thirty-four students completed the online questionnaire. All qualitative responses were placed into Weft QDA, an online, free, open-source tool used in the analysis of qualitative data. Once the data was uploaded, the researcher coded data into emerging themes. Upon completion of the coding process, the data was placed within a table designed to include quantitative data where appropriate. The inclusion of this table allowed the researcher to analyze both modes of data collection within the same spaces. This process provides more depth to the data collected.

\section{Results and Discussion}

Highlights of the dominant themes that emerged during the analysis of data are described below.

\section{Theme I: Learning Experiences of Online Research Students}

Data analysis established that both synchronous and asynchronous communication forms enhanced the learning experiences among students. Based on the comments from students, the use of asynchronous communication kept them up-to-date with their course expectations, resolved their fears, helped them to connect socially with their research supervisor, and provided beneficial feedback. Table 1 offers samples of students' responses in relation to the use of an asynchronous mode of communication. The responses suggest that the social presence of the research supervisor had an impact on the learning interaction experienced by students (Wei et al., 2012). 
Table 1

Comments from Students on the Use of Asynchronous Mode of Communication

\begin{tabular}{|l|l|}
\hline Student A & The communication process kept me on course. \\
\hline Student B & $\begin{array}{l}\text { Because of the feedback given, I was able to make the } \\
\text { necessary corrections which helped me to advance my } \\
\text { project. }\end{array}$ \\
\hline Student C & $\begin{array}{l}\text { My supervisor quieted my fears and gave me advice when it } \\
\text { was necessary. She also commended me when she was } \\
\text { pleased with the direction I was taking. }\end{array}$ \\
\hline Student D & $\begin{array}{l}\text { Communicating with my supervisor via email appears } \\
\text { more personal and effective than via forums. It is often } \\
\text { easier to check your e-mail than to log into the website, and } \\
\text { then search the forum for current info. }\end{array}$ \\
\hline Student E & I received prompt and beneficial feedback. \\
\hline
\end{tabular}

The data also established that the implementation of the synchronous mode of communication had significant benefits. For example, 30 students believed that the seminar presentation motivated them and kept them focused on their research projects. Despite this positive feedback, however, four students believed the seminars did not motivate them or keep them focused; external or internal factors could have influenced these perspectives. Additional research would be beneficial to establish the possible factors delimiting these students' motivation.

Combining both forms of communication proved beneficial. For example, the use of email and online discussion (asynchronous) provided a platform for individualized attention. The finding corroborated the idea put forward by Girard et al. (2007) that suggests that the fusion of both forms of communication (asynchronous and synchronous) could lead to greater virtual collaboration within the online learning community. This form of collaboration will be essential in providing students the sustaining communication within the learning environment that could enhance students' learning experiences. Importantly, it should also be noted that sustained communication could improve the social presence in the learning environment that could also result in the construction of knowledge within the learning community (Rockinson-Szapkiw, 2009).

The need for interaction within the learning environment is essential for the construction of knowledge (Rockinson-Szapkiw, 2009). Consequently, it is imperative that online discussions and email responses are humanized and developed to allow maximum interaction. To enhance the interaction, live seminar sessions were implemented. The data collected suggested that the implementation of these sessions improved students' experiences and helped motivate students as they developed their research projects. Table 2 highlights three dominant themes that emerged from the data in relation to the implementation of live seminar sessions. 
Table 2

Showing the Dominant Themes that Emerged with the Implementation of Live Online Seminar Sessions Using Blackboard Collaborate

\begin{tabular}{|c|c|}
\hline Themes & Students' comments \\
\hline Interaction & $\begin{array}{l}\text { Interaction among peers is important, "misery loves } \\
\text { company", but good to know our shortcomings exist and } \\
\text { learn from one another in rectifying them. } \\
\text { Interaction with colleagues. This aspect was lonely. I was } \\
\text { unable to communicate with colleagues from other groups, } \\
\text { so these live meetings made the course feel alive and } \\
\text { human. } \\
\text { It was nice hearing the voices of other participants. } \\
\text { I learned to use the Illuminate setting. It was comforting } \\
\text { hearing the voices of colleagues and my supervisor }\end{array}$ \\
\hline Knowledge building & $\begin{array}{l}\text { Clarification with areas of doubt. } \\
\text { Meaningful feedback from supervisor and classmates . } \\
\text { An opportunity to communicate verbally with the group } \\
\text { New ideas on how to proceed. } \\
\text { I was able to understand more clearly the concepts involve } \\
\text { in research methods. } \\
\text { Measure my progress as it relates to my colleagues. Garner } \\
\text { the support needed to move forward. } \\
\text { I was able to receive immediate feedback from my } \\
\text { supervisor and constructive criticisms from other students. } \\
\text { I was also able to give feedback to other students. There } \\
\text { was great clarity on the way forward having participated in } \\
\text { online meetings }\end{array}$ \\
\hline Response time & $\begin{array}{l}\text { Being able to ask questions and receive immediate } \\
\text { feedback. } \\
\text { Immediate responses to my questions. }\end{array}$ \\
\hline
\end{tabular}

On reflection, the synchronous mode of communication enhanced the learning experiences of online research students. The data in the table suggests that synchronous sessions can enhance student experiences by providing spaces for interaction. Ultimately, the design of these live sessions improved social presence and created a zone for learning and enhanced the intellectual exchanges within the learning environment (Whiteman, 2002; Newberry, 2001; and Rourke et al., 1999). 


\section{Theme II: Improving Interaction}

The issue of communicating online was also examined in this research. Twenty-nine percent of the students who did the survey stated that they found the online learning environment challenging. Based on the data collected, students had technical problems and difficulties with communicating with their research supervisors at some point during the course. For online students, this level of support is essential to keep them motivated and focused on their research project, particularly in the Caribbean where Internet service is not consistent.

The data analysis established that all research supervisors supported their students in the preparation of their online presentations (two sessions were held). However, it became apparent that this support was not consistent for both planned sessions held in J une and October. In J une, the seminar sessions were compulsory, but, in October, the guidance given to both supervisors and students did not indicate that the seminar sessions were compulsory. Therefore, some supervisors and students may have approached the second seminar in a more casual manner. Regardless of this discrepancy between the level of support given to students in seminars one and two, it is clear that $30(88 \%)$ of the students were satisfied with the level of support given throughout the research process. Four (11\%) of the thirty-four students believed that this support was inadequate. In a follow up statement on support, students were asked whether or not communication with their supervisors assisted with their research progress. Four of the thirty-four students indicated that online communication did not assist them with the research process.

The inclusion of the live online learning session created various opportunities for the students. Thirty of the thirty-four students agreed that the October seminar sessions helped motivate them and kept them focused on their research project. The issue of motivation is essential for the online learner because most of our online students are from different geographical regions of the Caribbean.

In contrast to earlier findings in the live online session, students who responded to the benefits of using email and online discussion made limited connections to social interaction within their responses. Since teaching and learning is a social activity, it is important to engage students and sustain this level of engagement (Yankee \& Baylor, 2006). As a result of this finding, strategies will be developed to foster better interaction in the online environment between research supervisors and their students to prevent students from feeling isolated. Kelly (2012) highlights this importance by stating that the humanized classroom leads to improved learning experiences, student accomplishment, and student retention. Moore and Kearsley (1996) stress that the learning space address the possible gaps between the learner and the instructor to develop interaction. 


\section{Conclusion}

One of the significant findings to emerge from this study is that the inclusion of synchronous and asynchronous strategies improved the learning experiences and interaction among research students and their supervisors by creating social interaction; these sessions also created the space for interaction between all 17 groups involved in writing their research projects.

The study has also shown that interaction with online research students will require different skill levels and aptitude to simulate and motivate students within the online learning environment. According to Fein and Logan (2003), online tutors need to be creative, have the ability to motivate and monitor their students, and help their students develop into critical learners so that they may provide "a style of education that excites and engages students" (Girard et al., 2007, p. 46).

Evidence from this study suggests that the preferred method of feedback for most students is email; therefore, research supervisors need to improve their support when using this form of communication. Live seminar sessions also benefitted students. Analyzed data established that the seminar sessions allowed the building of confidence within the learning environment and created a structure for students to manage their work effectively; some students also used these sessions to assess their own work and research progress.

The implementation of the synchronous and asynchronous strategies created a structure for the research coordinator to obtain ongoing feedback on students' progress and the support given by research supervisors. Therefore, the research coordinator should standardize the procedures used to ensure that the strategies employed become common practice when monitoring students and their supervisors online.

The research results also established that the synchronous and asynchronous strategies helped develop intellectual learning spaces for students. These learning spaces (online discussions and live web conferences) created a place for students to engage in discourses relevant to the research process. Research supervisors, therefore, should encourage student participation in all online discussions and web-based conferences. Additional web-based conferences could be a key tool in motivating and managing students' research projects.

In general, most research supervisors were supportive, although four students indicated that they had an unsupportive supervisor. Based on this finding, the research coordinator will need to create a monitoring tool with a design that addresses issues relating to student support.

The technological difficulties experienced by some students included the inability to log on for the live conference sessions, which could have affected their ability to communicate online and impeded their learning. 
This research has highlighted the importance and the need for a standardized use of synchronous and asynchronous strategies for monitoring students' and research coordinators' interaction and the development of online learning spaces to manage students' progress at various points in the research process. These findings also highlight the need to increase the number of online discussions and live presentations during the graduate research project course. The author recommends that further research solicits data from the research supervisors about their perception of synchronous and asynchronous strategies. 


\section{References}

Banks, F., Moon, B., \&Wolfenden, F. (2009). New modes of communication technologies and the reform of open and distance learning programmes: A response to the global crisis in teacher education and training. In 23rd ICDE World Conference on Open and Distance Learning, 8-10 J une 2009, Maastricht, The Netherlands. Retrieved from http:// oro.open.ac.uk/ 18345/

Baecher, H. (2011). The online "supplemental" workshop: Course enrichment to support novice teachers' analysis of classroom video. Merlot J ournal of Online Learning and Teaching, 7(1), 108-117.

Fein, A., \& Logan, M (2003). Preparing instructors for online instruction. In R. Aragon \&J . Bass, Facilitating learning in online environments. San Francisco: Wiley Periodicals.

Girard, J ., Willoughby, L., \& Berg, K. (2007). Video, voice and virtual collaboration: The 3v's of asynchronous education . In Buzze-More, Principles of effective online teaching. California: Informing Science Press.

J ohnson, S., \&Aragon S. (2003). An instructional strategy framework for online learning environments. In R. Aragon R \& J. Bass, Facilitating learning in online environments. San Francisco: Wiley Periodicals.

Perkins, D. N. (2001). Person-plus: A distributed view of thinking and learning. In G. Salomon (Ed.), Distributed cognition: Psychological and educational considerations (pp. 88- 110). Cambridge University Press.

Kelly, R. (2012). Tips for humanizing your online course. Online Classroom, 4-5.

Leung, H., Li, Q., \& Lau R., (2006). Advances in web based learning. ICWL $5^{\text {th }}$ International Conference, Penang, Malaysia, J uly 19-21

McPherson, M., \&Nunes, M. (2004). Developing innovation in online learning: An action research framework. London: RoutledgeFalmer.

Mok, M., \& Cheng, Y. (2000). Global knowledge, intelligence, and education for learning society. Invited plenary speech at the 6th UNESCO-ACEID International Conference "information Technologies in Educational Innovation for Development: Interfacing Global and Indigenous Knowledge”. Thailand.

Newberry, B. (2001). Raising student social presence in online classes." In WebNet 2001. Proceedings of the World Conference on the WWW and Internet. Norfolk, Va.: AACE 
Ragan, P., Lacey, A., \&Nagy, R. (2002). Web-based learning and teacher preparation: Stumbling blocks and stepping stones. Teaching with Technology Today, 8(5). Retrieved from http:// www.uwsa.edu/ttt/articles/ragan.htm

Rourke, L., Anderson, T., Garrisson, D., \&Archer, W. (1999). Assessing social presence in asynchronous text-based computer conferencing. J ournal of Distance Education, 14(2), 50-71.

Zhao, Y., Pugh, K., Sheldon, S., \& Byers, J . (2002). Conditions for classroom technology innovations. Teachers College Record, 104(3), 482-515.

Vannatta, R. (2000). Evaluation to planning: Technology integration in a school of education. J ournal of Technology and Teacher Education, 8(3), 231-246.

Wei, C., Chen, N., Kinshuk. (2012). A model for social presence in online classrooms. Educational Technology Research And Development [serial online], 60(3), 529-545. Available fromERIC, Ipswich, MA.

Yanghee, K., \& Baylor, A. (2006). A social-cognitive framework for pedagogical agents as learning companions. Association for Educational Communications and Technology, 8(54), 569-596.

\section{Athabasca University $\mathbf{I}$}

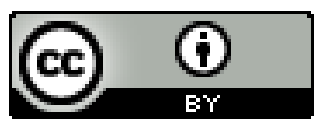

